\title{
Drug use patterns associated with risk of non-adherence to antiretroviral therapy among HIV-positive illicit drug users in a Canadian setting: a longitudinal analysis
}

Pouya Azar ${ }^{1}$, Evan Wood ${ }^{1,2}$, Paul Nguyen ${ }^{1}$, Maxo Luma', Julio Montaner ${ }^{1,2}$, Thomas Kerr ${ }^{1,2}$ and M-J Milloy ${ }^{1,2^{*}}$

\begin{abstract}
Background: Among people living with HIV/AIDS, illicit drug use is a risk for sub-optimal treatment outcomes. However, few studies have examined the relative contributions of different patterns of drug use on adherence to antiretroviral therapy (ART). We sought to estimate the effect of different types of illicit drug use on adherence in a setting of universal free HIV/AIDS treatment and care.

Methods: Using data from ongoing prospective cohorts of HIV-positive illicit drug users linked to comprehensive pharmacy dispensation records in Vancouver, Canada, we examined factors associated with $\geq 95 \%$ prescription refill adherence using generalized estimating equations (GEE) logistic regression.

Results: Between 1996 and 2013, 692 ART-exposed individuals were followed for a median of 42.7 months (Interquartile Range: $29.1-71.7$ ). In multivariable GEE analyses, heroin injection (Adjusted Odds Ratio $[A O R]=0.75,95 \%$ Confidence Interval [Cl]: 0.66-0.85) as well as cocaine injection $(A O R=0.80,95 \% \mathrm{Cl}: 0.72-0.90)$ were associated with lower likelihoods of optimal adherence. Methadone maintenance therapy ( $\mathrm{AOR}=1.88,95 \% \mathrm{Cl}: 1.68-2.11$ ) was associated with a greater likelihood of adherence.

Conclusions: Periods of heroin and cocaine injection appeared to have the most deleterious impact upon antiretroviral adherence. The findings point to the need for improved access to treatment for heroin use disorder, particularly methadone, and highlight the need to identify strategies to support ART adherence among cocaine injectors.
\end{abstract}

Keywords: HIV, Antiretroviral therapy, Illicit drug use, Heroin, Cocaine, Adherence

\section{Background}

The development of antiretroviral therapy (ART) has led to substantial declines in HIV/AIDS-associated morbidity and mortality among many groups in many settings worldwide [1]. Adherence to ART is the primary factor determining the degree and durability of optimal response to treatment, including achieving non-detectable levels of plasma HIV RNA. [2]. Studies indicate that up to $95 \%$ adherence is required to achieve maximum viral load suppression [3]. Suboptimal adherence is associated

\footnotetext{
* Correspondence: uhri-mjsm@cfenet.ubc.ca

'BC Centre for Excellence in HIV/AIDS, St. Paul's Hospital, 608-1081 Burrard Street, Vancouver, BC, Canada

${ }^{2}$ Division of AIDS, Department of Medicine, University of British Columbia, Vancouver, BC, Canada
}

with an increased risk of HIV/AIDS-associated mortality and morbidity [3] and elevated rates of viral resistance to treatment [4].

In many studies, active illicit drug use among individuals living with HIV/AIDS is associated with decreased access to HIV treatment, reduced medication adherence and increased mortality [5]. Although many studies have focused on the impact of heroin use on the clinical management of HIV infection [6,7] fewer studies have examined the influence of distinct illicit drug use patterns. Thus, we sought to examine the relative contribution of different illicit drug use patterns on ART non-adherence among a group of HIV-positive illicit drug users. 


\section{Methods}

Data for these analyses were derived from the Vancouver Injection Drug Users Study (VIDUS) and AIDS Care Cohort to evaluate Exposure to Survival Services (ACCESS), two ongoing prospective observational cohorts of illicit drug users in Vancouver, Canada. Beginning in 1996, persons who had injected illicit drugs other than cannabinoids in the previous month were recruited into VIDUS. Since 2005, persons who used illicit drugs and were HIV-seropositive at baseline or during the study are subsequently followed in ACCESS. Both cohorts use identical recruitment and follow-up procedures to allow for combined analyses.

Described in detail previously [8-10], the cohorts were populated through snowball sampling and extensive street outreach in the city's Downtown Eastside neighbourhood, an area with an open drug market and high levels of injection drug use, poverty and HIV infection $[11,12]$. Participants of these studies were 18 years of age or older and provided written informed consent. At baseline and every six-month follow-up interview, participants answered a standardized interviewer-administered questionnaire, were examined by a study nurse and provided blood samples for serologic analysis. Participants are actively referred to primary care services and drug treatment programs where available and were provided with a $\$ 30$ stipend per study visit. A unique feature of these studies is that the Canadian province of British Columbia delivers all HIV care including medications at no charge and employs a system in which every instance of antiretroviral dispensation and all HIV clinical monitoring is captured through a centralized registry $[8,13,14]$. This allows a comprehensive retrospective and prospective clinical HIV profile for all participants. Ethics approval has been provided annually by University of British Columbia/Providence Health Care Research Ethics Board.

The present analyses considered all HIV-seropositive participants who had been dispensed at least one day of antiretroviral therapy (ART) between May 1996 and May 2013. The primary outcome of interest in this study was adherence to ART in the six month period prior to each study interview. As in previous studies $[9,15]$, we estimated antiretroviral adherence using a validated measure based on pharmacy refill records provided by the confidential record linkage with the database of the Drug Treatment Program. Specifically, adherence was estimated by calculating the number of days for which an individual was dispensed ART in the previous six months over the number of days since they had initiated ART, capped at 180 days. We dichotomized this measure as $\geq 95 \%$ vs. $<95 \%$. The cut-off threshold of $95 \%$ was chosen as this level has previously been shown to be closely associated with virological suppression and survival $[15,16]$.
Explanatory variables of interest included sociodemographic data: age (per 10 years older), gender (female vs. male), and Caucasian ancestry (yes vs. no). Variables related to drug use characteristics included: heroin injection (yes vs. no), cocaine injection (yes vs. no), amphetamine injection (e.g., "speed", "uppers", crystal methamphetamine; yes vs. no), crack cocaine smoking (yes vs. no), and enrollment in methadone maintenance therapy (yes vs. no). All drug use characteristics defined above were treated as time-updated based on questionnaire data pertaining to the six month period prior to each study interview $[8,13]$. We also included CD4 cell count (per 100 cells/ $\mu \mathrm{L}$ increase) at ART initiation using the last CD4 cell count observation conducted prior to the first dispensation of ART. We also included a time-updated variable measuring the time since the participant initiated antiretroviral therapy (per year increase), using records from this setting's comprehensive antiretroviral dispensary.

As a first step, we visually inspected trends in the proportion of all participants reporting heroin injecting, cocaine injecting, crack smoking and amphetamine injecting at each interview period. Next, we visually inspected changes in median adherence rate at each interview period over time.

Since serial measures for each subject (i.e., multiple 6month observation periods) were available for many participants, we estimated the relationships between different socio-demographic, drug use and clinical factors and adherence using generalized estimating equations (GEE) with a logit-link function. As a first step, we conducted bivariable GEE analyses to determine which variables were statistically associated with adherence in unadjusted analyses. To adjust for potential confounding and identify factors that were associated with the outcome, all significant variables in the bivariable analyses were considered in the full multivariable model. With the drug use patterns being forced into the model, a backwards model selection procedure was used to identify the multivariate model with the best overall fit as indicated by the lowest quasilikelihood under the independence model criterion value. All statistical analyses were performed using the SAS software version 9.3 (SAS, Cary, NC). All $p$-values are two-sided.

\section{Results}

During the study period, 692 individuals were included in these analysis, among whom 213 (30.8\%) were female, the median age at baseline was 42 years (Inter-quartile Range (IQR): 35-47) and the median follow-up duration was 42.7 months (IQR: 29.1-71.7). At baseline (Table 1), $338(48.8 \%)$ individuals reported heroin injection in the previous six months, 388 (56.1\%) reported cocaine injection in the previous six months, 84 (12.1\%) reported amphetamine injection in the previous six months and 451 $(65.2 \%)$ reported smoking crack cocaine in the previous 
Table 1 Baseline characteristics of 692 HIV-positive illicit drug users stratified by adherence to ART in the previous six months

\begin{tabular}{|c|c|c|c|c|c|}
\hline \multirow[t]{2}{*}{ Characteristic } & \multirow{2}{*}{$\begin{array}{l}<95 \% \text { adherence } \\
301(43.5) \text { n (\%) }\end{array}$} & \multirow{2}{*}{$\begin{array}{l}\geq 95 \% \text { adherence } \\
392(56.6) \text { n (\%) }\end{array}$} & \multirow[t]{2}{*}{$\mathrm{OR}^{1}$} & \multirow[t]{2}{*}{$95 \% \mathrm{Cl}^{2}$} & \multirow[t]{2}{*}{$p$ value } \\
\hline & & & & & \\
\hline \multicolumn{6}{|l|}{ Age } \\
\hline Median (IQR) & $40(34-45)$ & $43(36-48)$ & 1.05 & $1.02-1.06$ & $<0.001$ \\
\hline \multicolumn{6}{|l|}{ Gender } \\
\hline Male & $195(64.8)$ & $284(72.6)$ & 1.00 & & \\
\hline Female & $106(35.2)$ & $107(27.5)$ & 0.69 & $0.50-0.96$ & 0.027 \\
\hline \multicolumn{6}{|l|}{ Caucasian ancestry } \\
\hline No & $143(47.5)$ & $140(35.8)$ & 1.00 & & \\
\hline Yes & $158(52.5)$ & $251(64.2)$ & 1.62 & $1.19-2.20$ & 0.002 \\
\hline \multicolumn{6}{|l|}{ Heroin injection ${ }^{3}$} \\
\hline No & $141(47.0)$ & $211(54.1)$ & 1.00 & & \\
\hline Yes & $159(53.0)$ & $179(45.9)$ & 0.75 & $0.56-1.02$ & 0.064 \\
\hline \multicolumn{6}{|l|}{ Cocaine injection ${ }^{3}$} \\
\hline No & $126(41.9)$ & $178(45.5)$ & 1.00 & & \\
\hline Yes & $175(58.1)$ & $213(54.5)$ & 0.86 & $0.64-1.17$ & 0.336 \\
\hline \multicolumn{6}{|l|}{ Amphetamine injection ${ }^{3}$} \\
\hline No & $271(90.0)$ & $337(86.2)$ & 1.00 & & \\
\hline Yes & $30(10.0)$ & $54(13.8)$ & 1.45 & $0.90-2.33$ & 0.125 \\
\hline \multicolumn{6}{|l|}{ Crack cocaine smoking ${ }^{3}$} \\
\hline No & $107(35.5)$ & $134(34.2)$ & 1.00 & & \\
\hline Yes & $194(64.5)$ & $257(65.7)$ & 1.06 & $0.77-1.45$ & 0.727 \\
\hline \multicolumn{6}{|l|}{$\mathrm{MMT}^{3}$} \\
\hline No & $202(67.1)$ & $210(53.7)$ & 1.00 & & \\
\hline Yes & 99 (32.9) & $181(46.3)$ & 1.76 & $1.29-2.40$ & $<0.001$ \\
\hline Time since ART initiation (per year) & $5.1(2.5-8.9)$ & $6.5(3.1-11.4)$ & 0.94 & $0.91-0.97$ & $<0.001$ \\
\hline \multicolumn{6}{|l|}{ Median (IQR) } \\
\hline \multicolumn{6}{|l|}{ CD4+ cells at ART initiation } \\
\hline Median (IQR) & $260(150-390)$ & $220(140-360)$ & 1.00 & $1.00-1.00$ & 0.074 \\
\hline
\end{tabular}

1. Odds Ratio; 2 . 95\% Confidence Interval; 3 . Refers to 180 day period prior to the baseline interview.

six months. The proportions of participants at each interview period reporting these drug use patterns are shown in Figure 1. Figure 2 depicts the median adherence rate for all participants at each interview period as well as the lower and upper quartiles. Over the entire study period, the median adherence rate was 98\% (Inter-Quartile Range [IQR]: 37, 100). Among all observation periods, 3073 (51\%) were characterized by $\geq 95 \%$ adherence. Correlation between the adherence rate and plasma HIV-1 RNA viral load (log10 transformed) was -0.67 ; correlation between the adherence rate and CD4+ cell count was 0.17 .

The bivariable and multivariable GEE analyses of adherence to ART are shown in Table 2. In the final multivariable model, heroin injection (Adjusted Odds Ratio $[\mathrm{AOR}]=0.76,95 \%$ Confidence Interval $[\mathrm{CI}]: 0.67-0.85)$, cocaine injection $(\mathrm{AOR}=0.74,95 \% \mathrm{CI}$ : 0.66-0.83), female sex $(A O R=0.77,95 \%$ CI: $0.68-0.87)$ and CD4 cell count at ART initiation $(\mathrm{AOR}=0.87,95 \% \mathrm{CI}: 0.83-0.92)$ were negatively associated with optimal adherence to ART. Older age $(\mathrm{AOR}=1.66,95 \% \mathrm{CI}: 1.54-1.80)$ and use of methadone maintenance therapy $(\mathrm{AOR}=1.88,95 \% \mathrm{CI}$ : $1.68-2.11$ ) were independently and positively associated with optimal adherence to ART.

\section{Discussion}

In this long-running community-recruited study of illicit drug users linked to comprehensive HIV clinical records in a setting of universal free HIV/AIDS treatment and care, we observed that periods of heroin and cocaine injection were independently and negatively associated with the likelihood of optimal adherence to ART. We did not observe a statistical relationship between periods 


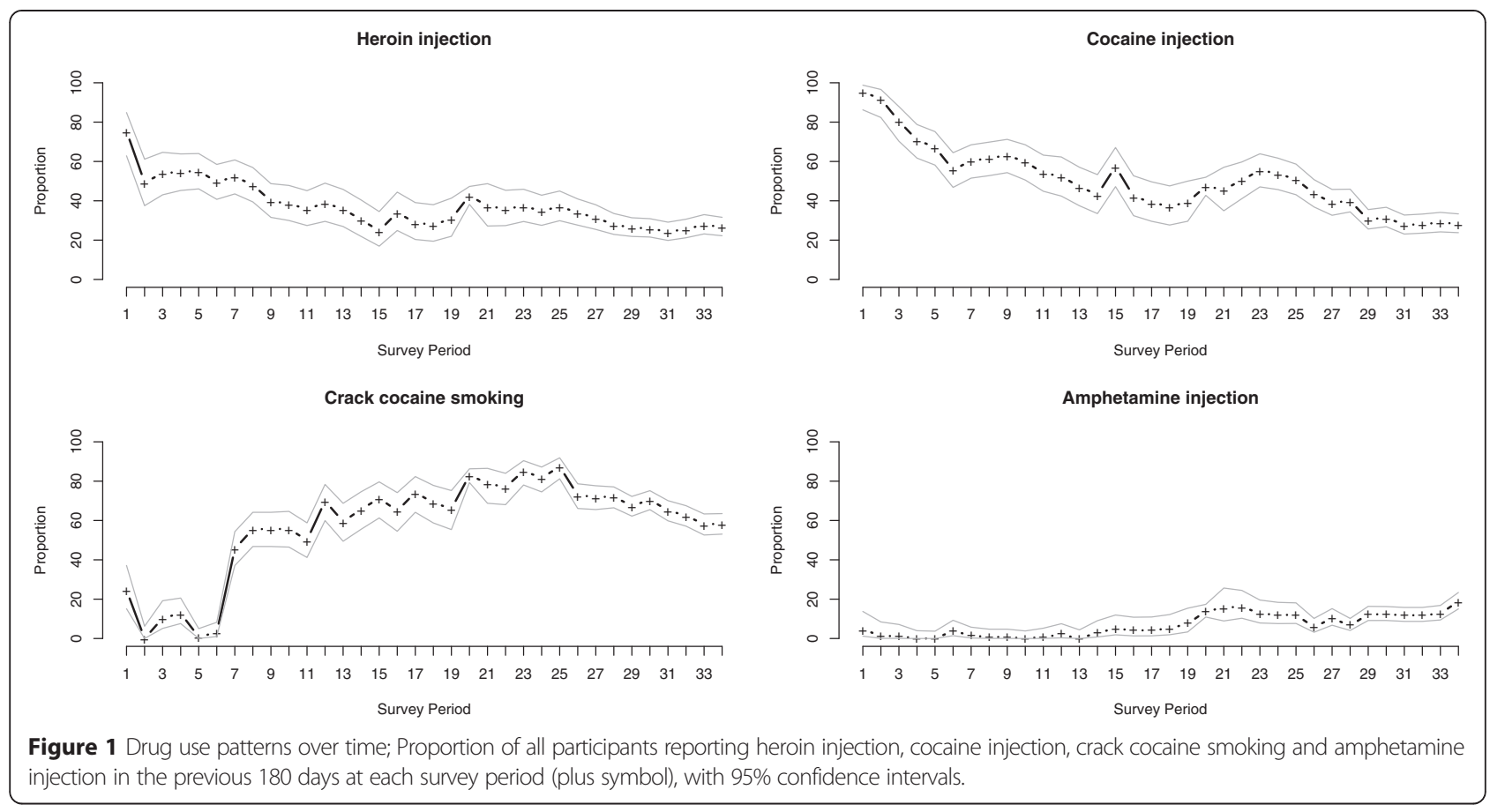

of either amphetamine injection or crack cocaine smoking and the likelihood of optimal adherence to ART. Meanwhile, engagement in methadone maintenance therapy was independently and positively associated with optimal adherence to ART.

Our finding of strong and independent links between heroin use, engagement in methadone maintenance and the likelihood of optimal ART adherence suggests that the expansion of evidence-based addiction treatment strategies, such as methadone, will likely improve retention in HIV/ AIDS care among opioid-dependent illicit drug users [17-19]. Improving access to methadone will require scale-up treatment slots in settings where methadone is currently available and removal of legal impediments to this evidence-based opioid treatment modality [20].

In our study, we did not observe a statistical relationship between amphetamine use and adherence to ART. Crystal methamphetamine use is particularly prevalent

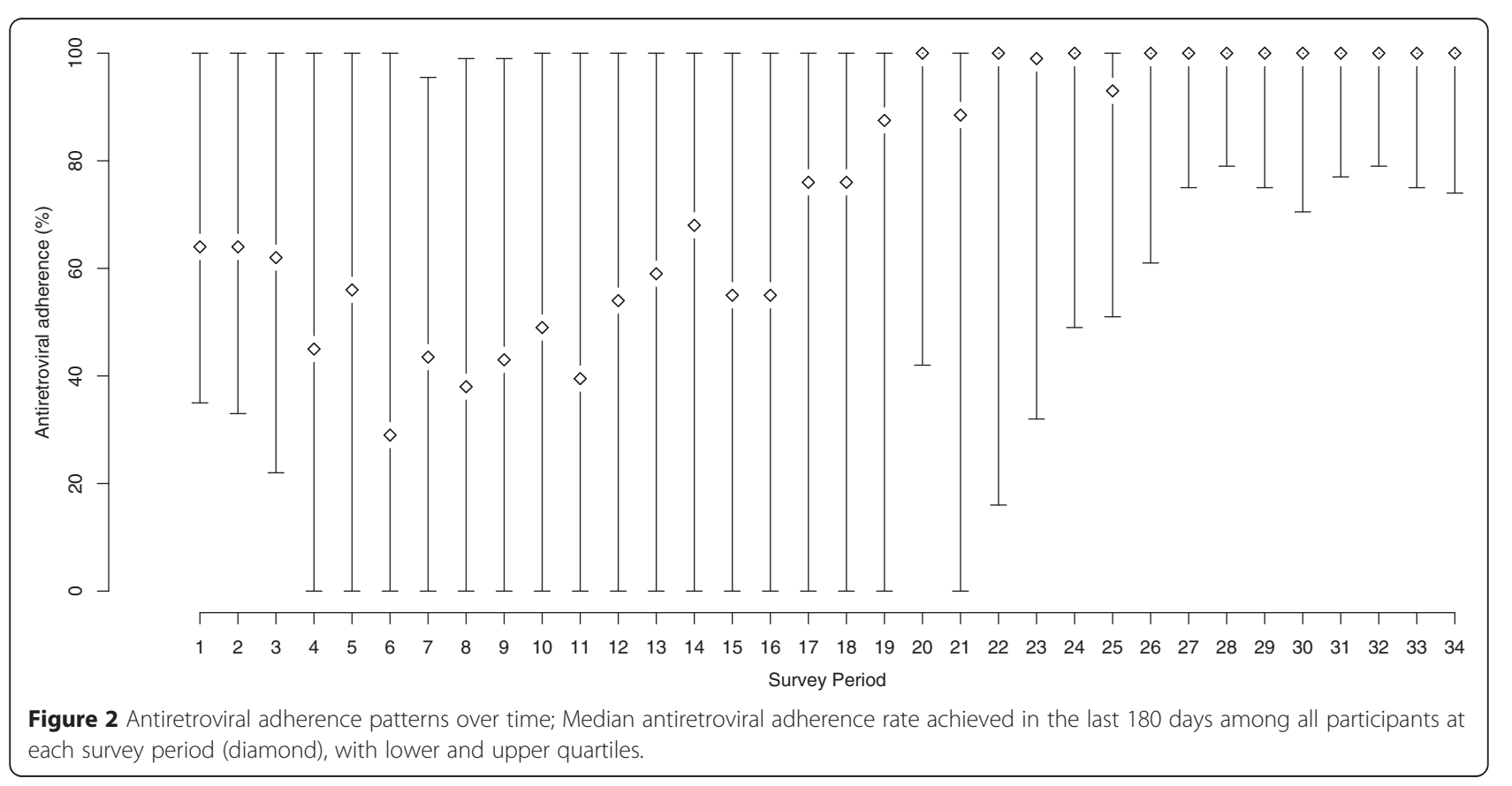


Table 2 Univariable and multivariable generalized estimating equations analyses of factors associated with $\geq 95 \%$ adherence to antiretroviral therapy among 692 illicit drug users

\begin{tabular}{|c|c|c|c|c|c|c|}
\hline Characteristic & $\mathrm{OR}^{1}$ & $95 \% \mathrm{Cl}^{2}$ & $p$ & $\mathrm{AOR}^{3}$ & $95 \% \mathrm{Cl}^{2}$ & $\mathrm{p}$ \\
\hline Gender (female vs. male) & 0.70 & $0.56-0.88$ & 0.002 & 0.77 & $0.68-0.87$ & 0.038 \\
\hline Age (per 10 years older) & 2.04 & $1.75-2.38$ & $<0.001$ & 1.66 & $1.54-1.80$ & $<0.001$ \\
\hline Caucasian (yes vs. no) & 1.37 & $1.12-1.69$ & 0.002 & 1.07 & $0.95-1.19$ & 0.571 \\
\hline Heroin injection (yes vs. no) ${ }^{4}$ & 0.67 & $0.58-0.78$ & $<0.001$ & 0.76 & $0.67-0.85$ & 0.002 \\
\hline Cocaine injection (yes vs. no) ${ }^{4}$ & 0.73 & $0.63-0.85$ & $<0.001$ & 0.74 & $0.66-0.83$ & 0.001 \\
\hline Amphetamine injection (yes vs. no) ${ }^{4}$ & 1.14 & $0.89-1.47$ & 0.305 & & & \\
\hline Crack cocaine smoking (yes vs. no) ${ }^{4}$ & 0.95 & $0.82-1.10$ & 0.525 & & & \\
\hline Methadone maintenance therapy (yes vs. no) ${ }^{4}$ & 1.74 & $1.45-2.10$ & $<0.001$ & 1.96 & $1.75-2.19$ & $<0.001$ \\
\hline Time since ART initiation (per year increase) & 1.08 & $1.06-1.11$ & $<0.001$ & 1.02 & $0.99-1.04$ & 0.090 \\
\hline CD4+ cell count at ART initiation (per 100 cells/mL increase) & 0.87 & $0.83-0.92$ & $<0.001$ & 0.88 & $0.85-0.90$ & $<0.001$ \\
\hline
\end{tabular}

1. Odds Ratio; 2. 95\% confidence interval; 3. Adjusted Odds Ratio; 4. Time-updated, refers to the six-month period prior to the interview.

among some populations of people living with HIV/ AIDS and persons at risk for HIV, especially men who have sex with men. [21-23] Numerous studies have found that, among this population, amphetamine use in is linked to decreased medication adherence as a result of binging episodes, and in the long-term, has been associated with the development of antiretroviral-resistant viral strains [23]. In the current study, which contained a high proportion of individuals reporting periods of polysubstance use, this association was not observed. This might reflect the relatively smaller number of individuals reporting periods of amphetamine injection and with cohorts of men who have sex with men, which would be more heterogeneous with respect to drug use. Instead, the present study observed a strong and independent link between injection cocaine use and sub-optimal adherence, underling the urgent need for effective pharmacotherapies to address stimulant use, especially in the context of HIV disease.

Although we observed increasing levels of adherence over time, a substantial proportion of all participants displayed sub-optimal adherence to prescribed treatment at every interview period. Our model indicates that specific drug use patterns each had different relationships to antiretroviral adherence. For example, while periods of heroin injection were $23 \%$ less likely to be characterized by $\geq 95 \%$ adherence, there was no significant difference between levels of optimal adherence during periods of amphetamine injection. Unfortunately, our model does not offer specific insights into possible explanations for these divergent results. Thus, future research should investigate the possible behavioural-, psychologic-, social- and structurallevel barriers and facilitators of adherence for different groups of illicit drug users in order to optimize substance abuse treatment and support ART adherence.

There are some limitations to this study to note. Participant selection for this observational study was not random and the results of this study cannot be generalized to the wider population of HIV-positive illicit drug users. Regarding associations drawn from the results of the study, there is potential for unmeasured confounding. In an attempt to minimize the impact of confounding on the observed relationships we used multivariable modelling. Also, we have previously observed that at least 95\% adherence to prescribed ART is strongly associated with viral suppression and survival $[15,16]$. Newer formulations of ART are more potent and evidence suggests they may deliver comparable rates of viral suppression at lower adherence thresholds [24,25]. Thus, future research might consider the effects of illicit drug use on attaining different adherence thresholds and viral suppression. Finally, we recognize that we are unable to determine the possible temporal relationships between illicit drug use behaviours and antiretroviral dispensation patterns within any 180-day observation period.

\section{Conclusions}

To conclude, our study utilized data from a long-running community-recruited prospective cohort of HIV-seropositive illicit drug users in the setting of free and universal access to HIV care. Periods of injection heroin use and injection cocaine use were both independently and negatively associated with a lower likelihood of optimal adherence to ART while engagement in MMT was associated with higher levels of optimal adherence. Given the importance of addressing substance use in the community and the proven success of MMT at reducing the risk of drugrelated harms, our findings support the need to spur efforts to improve access to treatment for problematic substance use among individuals living with HIV/AIDS.

\section{Competing interests}

Dr. Milloy is supported in part by the United States National Institutes of Health (R01-DA021525.) This work was supported in part by a Tier 1 Canada Research Chair in Inner-City Medicine awarded to Dr. Wood. Dr. Montaner is 
supported by the British Columbia Ministry of Health and through an Avant-Garde Award (No. 1DP1DA026182) from the National Institute of Drug Abuse (NIDA), at the US National Institutes of Health $(\mathrm{NIH})$. He has also received financial support from the International AIDS Society, United Nations AIDS Program, World Health Organization, National Institutes of Health Research-Office of AIDS Research, National Institute of Allergy \& Infectious Diseases, The United States President's Emergency Plan for AIDS Relief (PEPfAR), UNICEF, the University of British Columbia, Simon Fraser University, Providence Health Care and Vancouver Coastal Health Authority. The other authors declare they have no competing interests.

\section{Authors' contributions}

EW and PA conceived this study. PN conducted the statistical analyses. EW, $\mathrm{PA}, \mathrm{TK}, \mathrm{M}-\mathrm{JM}$ and $\mathrm{ML}$ contributed to the interpretation of the analyses; JSGM, $\mathrm{M}-\mathrm{JM}$, TK and EW contributed to the acquisition of data; PA drafted the manuscript and revised it; all authors provided commentary on the manuscript and gave final approval for the final version to be published.

\section{Acknowledgements}

The authors thank the study participants for their contributions to the research, as well as current and past researchers and staff. We would specifically like to thank: Kristie Starr, Deborah Graham, Tricia Collingham, Carmen Rock, Brandon Marshall, Caitlin Johnston, Steve Kain, Benita Yip and Guillaume Colley for their research and administrative assistance. The study is supported by the US National Institutes of Health (R01-DA021525) and the Canadian Institutes of Health Research (MOP-79297 and RAA-79918. The funders had no role in the design of the study; collection, analysis and interpretation of data; in the writing of the manuscript; and in the decision to submit the manuscript for publication.

Received: 29 August 2014 Accepted: 25 March 2015

Published online: 18 April 2015

\section{References}

1. Zwahlen M, Harris R, May M, Hogg R, Costagliola D, de Wolf F, et al. Mortality of HIV-infected patients starting potent antiretroviral therapy: comparison with the general population in nine industrialized countries. Int J Epidemiol. 2009;38:1624-33.

2. Wood E, Hogg RS, Yip B, Harrigan PR, Montaner J. Why are baseline HIV RNA levels 100,000 copies/mL or greater associated with mortality after the initiation of antiretroviral therapy? J Acquir Immune Defic Syndr. 2005;38:289-95.

3. Paterson DL, Swindells S, Mohr J, Brester M, Vergis EN, Squier C, et al. Adherence to protease inhibitor therapy and outcomes in patients with HIV infection. Ann Intern Med. 2000;133:21-30.

4. Deeks SG. Treatment of antiretroviral-drug-resistant HIV-1 infection. Lancet. 2003:362:2002-11.

5. Malta M, Strathdee SA, Magnanini MMF, Bastos FI. Adherence to antiretroviral therapy for human immunodeficiency virus/acquired immune deficiency syndrome among drug users: a systematic review. Addiction. 2008;103:1242-57.

6. Carrieri MP, Tamalet C, Vlahov D, Yahi N, Chesney M, Moatti JP. Relationship between HIV-1 viral load and continued drug use in untreated infected injection drug users. Addict Biol. 1999:4:197-202.

7. Lucas GM. Substance abuse, adherence with antiretroviral therapy, and clinical outcomes among HIV-infected individuals. Life Sci. 2011;88:948-52.

8. Strathdee SA, Palepu A, Cornelisse PG, Yip B, O'Shaughnessy MV, Montaner $J S$, et al. Barriers to use of free antiretroviral therapy in injection drug users. JAMA. 1998;280:547-9.

9. Wood E, Hogg RS, Lima VD, Kerr T, Yip B, Marshall BDL, et al. Highly active antiretroviral therapy and survival in HIV-infected injection drug users. JAMA. 2008;300:550-4.

10. Wood E, Hogg RS, Bonner S, Kerr T, Li K, Palepu A, et al. Staging for antiretroviral therapy among HIV-infected drug users. JAMA. 2004:292:1175-7.

11. Strathdee SA, Patrick DM, Currie SL, Cornelisse PG, Rekart ML, Montaner JS, et al. Needle exchange is not enough: lessons from the Vancouver injecting drug use study. AIDS. 1997;11:F59-65.

12. Tyndall MW, Currie S, Spittal P, Li K, Wood E, O apos Shaughnessy MV, et al. Intensive injection cocaine use as the primary risk factor in the Vancouver HIV-1 epidemic. AIDS. 2003;17:887-93.

13. Palepu A, Tyndall MW, Joy R, Kerr T, Wood E, Press N, et al. Antiretroviral adherence and HIV treatment outcomes among HIV/HCV co-infected injection drug users: the role of methadone maintenance therapy. Drug Alcohol Depend. 2006;84:188-94.
14. Wood E, Hogg RS, Harrigan PR, Montaner JSG. When to initiate antiretroviral therapy in HIV-1-infected adults: a review for clinicians and patients. Lancet Infect Dis. 2005;5:407-14.

15. Wood E, Hogg RS, Yip B, Harrigan PR, O'Shaughnessy MV, Montaner JSG. Effect of medication adherence on survival of HIV-infected adults who start highly active antiretroviral therapy when the CD4+ cell count is 0.200 to 0.350 x 10(9) cells/L. Ann Intern Med. 2003;139:810-6.

16. Wood E, Montaner JSG, Yip B, Tyndall MW, Schechter MT, O'Shaughnessy $\mathrm{MV}$, et al. Adherence to antiretroviral therapy and CD4 T-cell count responses among HIV-infected injection drug users. Antivir Ther. 2004;9:229-35.

17. Negus SS, Banks ML. Medications development for opioid abuse. Cold Spring Harb Perspect Med. 2013;3:a012104-4.

18. Spire B, Lucas GM, Carrieri MP. Adherence to HIV treatment among IDUs and the role of opioid substitution treatment (OST). Int J Drug Policy. 2007;18:262-70.

19. Strain EC, Bigelow GE, Liebson IA, Stitzer ML. Moderate- vs high-dose methadone in the treatment of opioid dependence: a randomized trial. JAMA. 1999;281:1000-5.

20. Wolfe D, Carrieri MP, Shepard D. Treatment and care for injecting drug users with HIV infection: a review of barriers and ways forward. Lancet. 2010;376:355-66.

21. Carrico AW, Woolf-King SE, Neilands TB, Dilworth SE, Johnson MO. Stimulant use and HIV disease management among men in same-sex relationships. Drug Alcohol Depend. 2014;139:174-7.

22. Marquez C, Mitchell SJ, Hare CB, John M, Klausner JD. Methamphetamine use, sexual activity, patient-provider communication, and medication adherence among HIV-infected patients in care, San Francisco 2004-2006. AIDS Care. 2009;21:575-82.

23. Reback CJ, Larkins S, Shoptaw S. Methamphetamine abuse as a barrier to HIV medication adherence among gay and bisexual men. AIDS Care. 2003;15:775-85.

24. Hughes CA, Robinson L, Tseng A, MacArthur RD. New antiretroviral drugs: a review of the efficacy, safety, pharmacokinetics, and resistance profile of tipranavir, darunavir, etravirine, rilpivirine, maraviroc, and raltegravir. Expert Opin Pharmacother. 2009;10:2445-66.

25. Maggiolo F, Airoldi M, Kleinloog HD, Callegaro A, Ravasio V, Arici C, et al. Effect of adherence to HAART on virologic outcome and on the selection of resistance-conferring mutations in NNRTI- or PI-treated patients. HIV Clin Trials. 2007;8:282-92

\section{Submit your next manuscript to BioMed Central and take full advantage of:}

- Convenient online submission

- Thorough peer review

- No space constraints or color figure charges

- Immediate publication on acceptance

- Inclusion in PubMed, CAS, Scopus and Google Scholar

- Research which is freely available for redistribution 